\title{
Universal scaling of respiratory metabolism, size and nitrogen in plants
}

\author{
Peter B. Reich ${ }^{1}$, Mark G. Tjoelker ${ }^{2}$, Jose-Luis Machado ${ }^{3} \&$ Jacek Oleksyn ${ }^{4}$
}

The scaling of respiratory metabolism to body size in animals is considered to be a fundamental law of nature ${ }^{1-11}$, and there is substantial evidence for an approximate $\frac{3}{4}$-power relation. Studies suggest that plant respiratory metabolism also scales as the $\frac{3}{4}$-power of mass ${ }^{12-14}$, and that higher plant and animal scaling follow similar rules owing to the predominance of fractal-like transport networks and associated allometric scaling ${ }^{8-14}$. Here, however, using data obtained from about 500 laboratory and fieldgrown plants from 43 species and four experiments, we show that whole-plant respiration rate scales approximately isometrically (scaling exponent $\approx 1$ ) with total plant mass in individual experiments and has no common relation across all data. Moreover, consistent with theories about biochemically based physiological scaling ${ }^{15-18}$, isometric scaling of whole-plant respiration rate to total nitrogen content is observed within and across all data sets, with a single relation common to all data. This isometric scaling is unaffected by growth conditions including variation in light, nitrogen availability, temperature and atmospheric $\mathrm{CO}_{2}$ concentration, and is similar within or among species or functional groups. These findings suggest that plants and animals follow different metabolic scaling relations, driven by distinct mechanisms.

Abundant evidence indicates that diverse fundamental characteristics of animals and plants, including physiological, morphological and allometric attributes, scale with increasing size ${ }^{1-14}$, as described by power laws of the form:

$$
Y=Y_{0} M^{b}
$$

where $Y$ is an attribute such as metabolic rate, $Y_{0}$ is a normalization constant, $M$ is body mass, and $b$ is the scaling exponent. Perhaps the most fundamental of all such relationships is the one relating wholeorganism metabolic rates of animals as the $\sim \frac{3}{4}$-power of body size ${ }^{1-4}$; in other words, with each 10-fold increase in size, metabolic rate increases by 7.5 -fold. This has been shown to be true for basal metabolism and field metabolism in animals, and for numerous endothermic and ectothermic organisms ${ }^{1-4}$. Although it was originally expected that these allometric scaling laws would follow a $\frac{2}{3}$ exponent because of the Euclidean surface-area rule $\mathrm{e}^{2-4}$, the preponderance of data ${ }^{1-4}$ suggest that the exponent is $\frac{3}{4}$, although vigorous debate continues on this point ${ }^{5-7}$.

Some argue that $\frac{3}{4}$-power allometric scaling in biology is so pervasive that various allometric relations probably have a common, mechanistic origin ${ }^{4,8,9}$. Thus, there has been a surge in theoretical work aimed at explaining scaling relations ${ }^{8-11}$, as well as debate about the predictive value and validity of such models ${ }^{5-7,19}$. The disproportionate increase (less than isometric) in metabolism with increasing size has been explained by various metabolic scaling theories ${ }^{8-11}$, including one based on the fractal-like design of exchange surfaces and space-filling resource distribution networks, such as the animal vascular system. This theory suggests that physiology is constrained by hierarchical branching networks that optimally supply resources to all parts of three-dimensional organisms, and that such constraints are similar for vascular plants as they are for animals ${ }^{8,9}$. Evidence indicates that allometric and physiological scaling in plants often follow $\frac{3}{4}$-power laws similar to those found for animals ${ }^{12,20-25}$. A hierarchically branched model of plant geometry and hydraulics predicted that whole-plant metabolism would scale to the $\frac{3}{4}$-power with mass, but there were no empirical data available to test this particular prediction ${ }^{12}$.

A subsequent model, based on published metabolic (that is, basal respiration for animals, dark respiration for plants) rates of diverse taxa, predicted a common $\frac{3}{4}$-power size-dependent scaling (as well as common temperature-dependent scaling) for unicellular organisms, plants and animals ${ }^{13}$. This 'universal' relationship has been developed in various forms in subsequent publications ${ }^{14,26}$, further contributing to the notion of common size-dependent scaling in plants and animals. However, the plant data used in establishing these models and estimates ${ }^{13,14}$ were sparse and disparate: they included observations of 20 different individual plants or plant parts, including fruits, seeds and storage organs, and three small individuals of one species, measured at different temperatures and sizes ${ }^{13}$. Thus, a more comprehensive test of predicted metabolism-size scaling relations in plants is needed that encompasses a wider array of taxa and environmental conditions.

To address this information gap and to test both prior theoretical predictions $^{12,13}$ and hypotheses about the biochemical control of the scaling of plant respiration ${ }^{15-18}$, here we present data for $\sim 500$ observations from 43 perennial plant species of coupled measurements of whole-plant dry mass, nitrogen $(\mathrm{N})$ content and respiration rate from four separate studies of laboratory and wild field-grown plants that ranged in age from 1 month to $25 \mathrm{yr}$ (see Methods and Supplementary Information). The data include a wide range of species and functional groups, and plants were grown under a heterogeneous set of environmental conditions that included experimentally controlled contrasts involving temperature, light, $\mathrm{N}$ supply and atmospheric $\mathrm{CO}_{2}$ concentration. Moreover, we assess aboveground data separately to enable the inclusion of published aboveground respiration data for an additional ten large trees ${ }^{27,28}$ to extend the size range of our analyses. Collectively, the observations span five of the roughly 12 orders of magnitude of size in vascular plants ${ }^{22}$.

The results of each experiment do not support the idea of $\frac{3}{4}$-power scaling and instead are consistent with approximately isometric (exponent $\approx 1.0$ ) scaling of respiration to body mass for whole plants (Tables 1 and 2, and Fig. 1a). For the four independent studies, the mean scaling exponent of respiration to mass was 1.04, and twotailed $t$-tests show the average exponent among the four studies to be

'Department of Forest Resources, University of Minnesota, St Paul, Minnesota 55108, USA. ${ }^{2}$ Department of Forest Science, Texas A\&M University, College Station, Texas 77843, USA. ${ }^{3}$ Department of Biology, Swarthmore College, Swarthmore, Pennsylvania 19081, USA. ${ }^{4}$ Polish Academy of Sciences, Institute of Dendrology, PL-62-035 Kornik, Poland. 
Table 1 | Scaling of whole-plant respiration and dry mass by experiment and environment

\begin{tabular}{|c|c|c|c|c|c|c|c|}
\hline Study & Treatment or growth condition & $n$ & Intercept & Exponent & Lower $\mathrm{Cl}$ & Upper Cl & $r$ \\
\hline Field/US tree saplings & All & 119 & 0.391 & 1.117 & 1.052 & 1.185 & 0.951 \\
\hline $\mathrm{GH} /$ tree seedlings & All & 165 & 1.345 & 1.037 & 1.002 & 1.073 & 0.976 \\
\hline $\mathrm{GC} /$ tree seedlings & All & 190 & 1.472 & 1.058 & 1.021 & 1.097 & 0.970 \\
\hline Lab/all & All indoor seedlings & 417 & 1.426 & 1.047 & 1.023 & 1.073 & 0.970 \\
\hline $\begin{array}{l}\text { Field/US tree saplings } \\
\text { Field/US tree saplings }\end{array}$ & $\begin{array}{l}\text { Understory } \\
\text { Small gap }\end{array}$ & $\begin{array}{l}77 \\
42\end{array}$ & $\begin{array}{l}0.389 \\
0.426\end{array}$ & $\begin{array}{l}1.110 \\
1.120\end{array}$ & $\begin{array}{l}1.017 \\
1.017\end{array}$ & $\begin{array}{l}1.190 \\
1.233\end{array}$ & $\begin{array}{l}0.947 \\
0.958\end{array}$ \\
\hline $\begin{array}{l}\mathrm{GC} / \text { tree seedlings } \\
\mathrm{GC} / \text { tree seedlings }\end{array}$ & $\begin{array}{l}\text { Ambient } \mathrm{CO}_{2} \\
\text { Increased } \mathrm{CO}_{2}\end{array}$ & $\begin{array}{l}96 \\
94\end{array}$ & $\begin{array}{l}1.476 \\
1.468\end{array}$ & $\begin{array}{l}1.058 \\
1.060\end{array}$ & $\begin{array}{l}1.003 \\
1.008\end{array}$ & $\begin{array}{l}1.115 \\
1.114\end{array}$ & $\begin{array}{l}0.969 \\
0.972\end{array}$ \\
\hline $\begin{array}{l}\mathrm{GC} / \text { tree seedlings } \\
\mathrm{GC} / \text { tree seedlings } \\
\mathrm{GC} / \text { tree seedlings }\end{array}$ & $\begin{array}{l}18 / 12^{\circ} \mathrm{C} \\
24 / 18^{\circ} \mathrm{C} \\
30 / 24^{\circ} \mathrm{C}\end{array}$ & $\begin{array}{l}63 \\
64 \\
63\end{array}$ & $\begin{array}{l}1.549 \\
1.469 \\
1.382\end{array}$ & $\begin{array}{l}1.000 \\
1.050 \\
1.110\end{array}$ & $\begin{array}{l}0.935 \\
0.996 \\
1.060\end{array}$ & $\begin{array}{l}1.070 \\
1.107 \\
1.163\end{array}$ & $\begin{array}{l}0.968 \\
0.979 \\
0.984\end{array}$ \\
\hline $\begin{array}{l}\mathrm{GH} / \text { herb seedlings } \\
\mathrm{GH} / \text { herb seedlings }\end{array}$ & $\begin{array}{l}\text { Ambient N } \\
\text { Added N }\end{array}$ & $\begin{array}{l}31 \\
31\end{array}$ & $\begin{array}{l}1.335 \\
1.464\end{array}$ & $\begin{array}{l}0.925 \\
0.928\end{array}$ & $\begin{array}{l}0.849 \\
0.865\end{array}$ & $\begin{array}{l}1.008 \\
0.996\end{array}$ & $\begin{array}{l}0.976 \\
0.983\end{array}$ \\
\hline
\end{tabular}

All equations were fitted by the log-log version of the equation: $Y=Y M^{b}$. Reduced major axis intercepts and slopes (exponents) are shown, as well as the lower and upper $95 \% \mathrm{Cl}$ of the exponent and the Pearson correlation coefficient ( $r$ ). Field/US tree saplings, field study of saplings of four tree species; GH/tree seedlings, greenhouse study of seedlings of nine tree species; $\mathrm{GC} /$ tree seedlings, growth chamber study of seedlings of five tree species; $\mathrm{GH} /$ herb seedlings, greenhouse study of seedlings of 32 herbaceous species; $n$, number of observations.

significantly different from $0.75(P=0.002)$ but not from 1.0 $(P=0.244)$.

A robust test of scaling relationships is whether they are consistent within narrow and broad comparative groupings by growth environment or taxa. In each study, relations for plants in contrasting environments (high versus low light, differing atmospheric $\mathrm{CO}_{2}$ concentration, temperature or $\mathrm{N}$ supply) or different functional groups had similar scaling slopes, with the position of the lines (that is, the intercepts) showing greater variability (Tables 1 and 2). Among our three studies involving woody plants, we could evaluate the whole-plant metabolism versus mass scaling relationship at the species level for 16 cases, each representing a different individual species by experiment combination (ten species, some repeated in more than one study). For those 16 relationships (Table 2), the mean scaling exponent was 1.03 (95\% confidence interval $(\mathrm{CI})=0.94$ $1.11)$, which was significantly different from $0.75(P<0.0001)$, but not from $1.0(P=0.526)$.

A common metabolism-size relationship fitted all first-year greenhouse and growth chamber plants pooled $(n=417$, scaling exponent $=1.05$; Table 1 and Fig. 1a), even though the data included tree, grass and forb species grown under differing environmental conditions in distinct experiments. Older, field-grown plants (US tree saplings) had a scaling slope of respiration to plant mass similar to that of the greenhouse and growth chamber plants. However, the field-grown plants had an intercept of this relation that was markedly different to that of the laboratory plants (Fig. 1a); thus, whole-plant respiration rates at any given size were lower for the field-grown plants than the laboratory plants (Fig. 1a). In addition, both the fieldgrown saplings (US tree saplings) and larger trees (Japan trees) had much greater above-ground biomass at a common above-ground respiration rate than did the laboratory-grown plants (Fig. 1d).

Fitting a relationship of respiration to mass across all available data yields scaling exponents of $0.81(95 \% \mathrm{CI}=0.79-0.84)$ and $0.84(95 \%$ $\mathrm{CI}=0.82-0.86)$ for the whole-plant and above-ground data sets, respectively. However, plots of residuals versus predicted values show non-constant residual mean and residual variance functions, indicating that a single overall model fit is inappropriate. This is because these correlations are fitted across data sets with similar slopes but different intercepts (Fig. 1a, d). It is therefore difficult to quantify a comprehensive relationship of respiration to plant mass across all plant sizes and growth environments, although a scaling exponent of $<1$ across the full range of plant sizes is consistent with the widely held notion that the fraction of tissues with low respiration rate (such as boles of large trees) increases with plant size. However, even ignoring statistical concerns, which could be a result of the nature of our data compilations, a different slope across all data $(\sim 0.81-0.84)$

Table 2 | Scaling of whole-plant respiration and dry mass by species and functional group

\begin{tabular}{|c|c|c|c|c|c|c|c|}
\hline Study & Group or Species & $n$ & Intercept & Exponent & Lower $\mathrm{Cl}$ & Upper Cl & $r$ \\
\hline $\mathrm{GH} /$ herb seedlings & Grasses & 32 & 1.424 & 0.961 & 0.860 & 1.074 & 0.959 \\
\hline $\mathrm{GH} /$ herb seedlings & Forbs & 30 & 1.444 & 0.973 & 0.915 & 1.036 & 0.987 \\
\hline Field/US tree saplings & Abies balsamifera & 35 & 0.019 & 1.293 & 1.198 & 1.394 & 0.978 \\
\hline Field/US tree saplings & Acer rubrum & 35 & 0.277 & 1.189 & 1.059 & 1.336 & 0.951 \\
\hline Field/US tree saplings & Betula papyrifera & 14 & 1.108 & 0.714 & 0.631 & 0.807 & 0.982 \\
\hline Field/US tree saplings & Pinus strobus & 35 & 0.250 & 1.183 & 1.091 & 1.283 & 0.975 \\
\hline $\mathrm{GH} /$ tree seedlings & Betula alleghaniensis & 9 & 1.379 & 0.923 & 0.827 & 1.030 & 0.998 \\
\hline $\mathrm{GH} /$ tree seedlings & Betula papyrifera & 35 & 1.374 & 0.934 & 0.889 & 0.981 & 0.991 \\
\hline $\mathrm{GH} /$ tree seedlings & Larix laricina & 18 & 1.402 & 1.017 & 0.921 & 1.122 & 0.983 \\
\hline $\mathrm{GH} /$ tree seedlings & Picea glauca & 13 & 1.428 & 1.233 & 0.920 & 1.652 & 0.919 \\
\hline $\mathrm{GH} /$ tree seedlings & Pinus banksiana & 19 & 1.436 & 1.110 & 0.863 & 1.428 & 0.901 \\
\hline $\mathrm{GH} /$ tree seedlings & Pinus strobus & 23 & 1.373 & 1.237 & 1.099 & 1.391 & 0.968 \\
\hline $\mathrm{GH} /$ tree seedlings & Populus tremuloides & 34 & 1.397 & 0.917 & 0.873 & 0.963 & 0.991 \\
\hline $\mathrm{GC} /$ tree seedlings & Betula papyrifera & 36 & 1.512 & 0.882 & 0.834 & 0.932 & 0.988 \\
\hline $\mathrm{GC} /$ tree seedlings & Larix laricina & 40 & 1.359 & 0.927 & 0.874 & 0.984 & 0.984 \\
\hline $\mathrm{GC} /$ tree seedlings & Picea mariana & 42 & 1.284 & 0.967 & 0.888 & 1.053 & 0.967 \\
\hline $\mathrm{GC} /$ tree seedlings & Pinus banksiana & 42 & 1.325 & 0.990 & 0.923 & 1.062 & 0.977 \\
\hline $\mathrm{GC} /$ tree seedlings & Populus tremuloides & 30 & 1.714 & 0.906 & 0.853 & 0.963 & 0.988 \\
\hline
\end{tabular}

The studies, analyses and abbreviations are as in Table 1. Two species in the $\mathrm{GH} /$ tree seedling study had either insufficient sample size or a non-significant relation and are not included. 

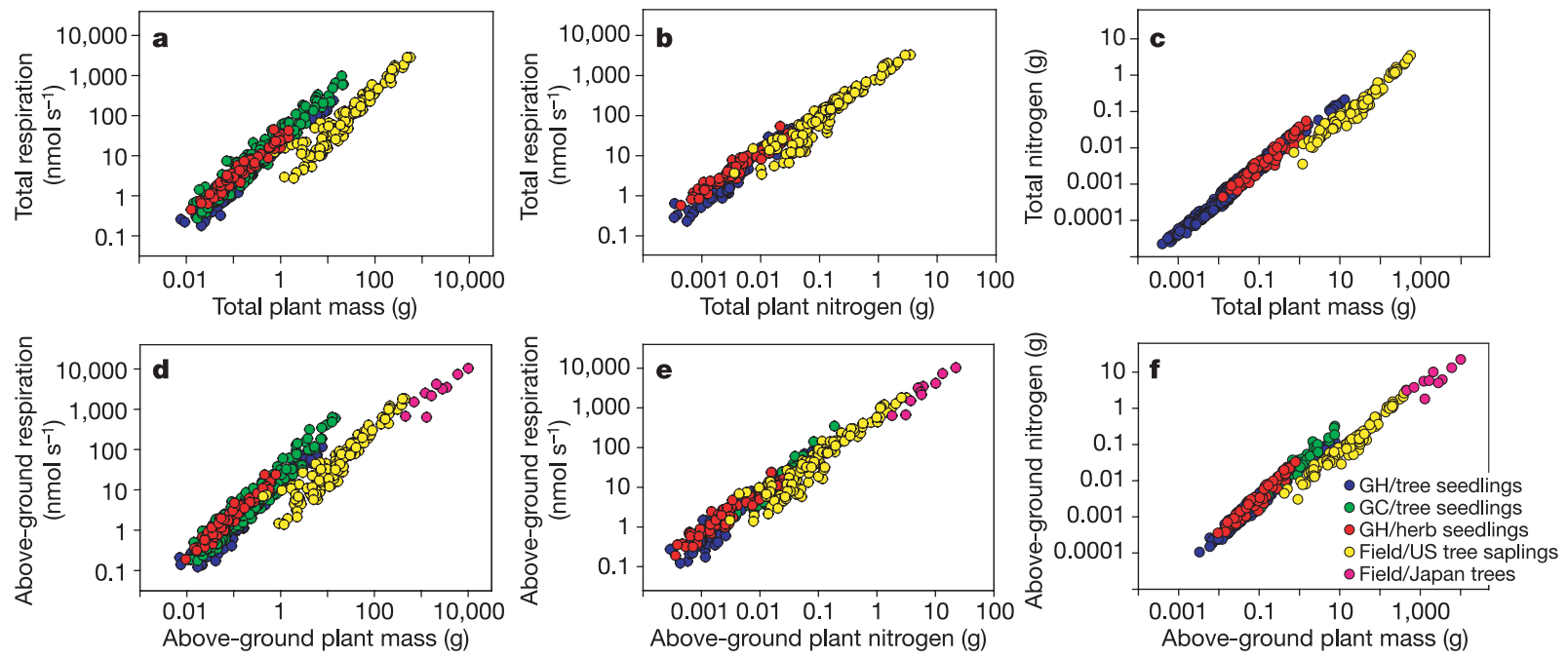

Figure 1 | Scaling of respiration, $\mathbf{N}$ and plant mass for plants. Data are from studies of field, greenhouse $(\mathrm{GH})$ and growth chamber $(\mathrm{GC})$ plants. a, Whole-plant respiration in relation to total plant dry mass. $\mathbf{b}$, Wholeplant respiration in relation to whole-plant N. c, Whole-plant $\mathrm{N}$ in relation to total plant dry mass. d, Above-ground plant respiration in relation to

above-ground plant dry mass. e, Above-ground plant respiration in relation to above-ground plant $\mathrm{N}$. $f$, Above-ground plant $\mathrm{N}$ in relation to aboveground plant dry mass. Respiration, determined as net $\mathrm{CO}_{2}$ efflux, was adjusted to a common measurement temperature (see Methods and Supplementary Information). See Tables 1-3 for details.

from that within data sets $(\sim 1.00-1.05)$ is inconsistent with the idea of a general relation involving size per se.

In contrast to the lack of a single universal relationship between plant respiration and plant mass, the data for all plants from all studies, including field and laboratory, are described by a single, common relationship between total respiration and total plant $\mathrm{N}$ content (Fig. 1b) or above-ground respiration and above-ground $\mathrm{N}$ content (Fig. 1e). The scaling exponents of these relationships (Table 3 and Fig. 1) are nearly 1.0 (for example, for total plant data, exponent $=1.03,95 \% \mathrm{CI}=1.00-1.05)$. Thus, the relationship between respiration and $\mathrm{N}$ content reconciles intercept differences among studies observed for the respiration versus plant mass relationships. These results are consistent with the fundamental role of $\mathrm{N}$ in the biochemistry of plant respiration and strong evidence for universal relations between respiration and $\mathrm{N}$ in higher plants ${ }^{15-18}$.

Total plant $\mathrm{N}$ also scaled nearly isometrically with total dry mass in our individual studies (average exponent $\approx 0.98$ for the four studies; Table 3 and Fig. 1c). Similar to respiration, however, field-grown tree saplings in a Minnesota forest and plantation-grown trees in Japan had lower plant $\mathrm{N}$ content at a given plant mass (that is, they had

Table 3 | Scaling of plant $\mathbf{N}$ with plant respiration and dry mass

\begin{tabular}{lrccccc}
\hline Study & $n$ & Intercept & Exponent & Lower Cl & Upper Cl & $r$ \\
\hline $\begin{array}{l}\text { Plant N versus plant mass } \\
\text { Field/US tree saplings }\end{array}$ & 118 & -2.197 & 0.945 & 0.908 & 0.983 & 0.977 \\
GH/tree seedlings & 460 & -1.631 & 0.920 & 0.910 & 0.931 & 0.993 \\
GC/tree seedlings & 46 & -1.528 & 1.060 & 0.971 & 1.156 & 0.961 \\
GH/herb seedlings & 63 & -1.517 & 1.003 & 0.944 & 1.066 & 0.973 \\
$\begin{array}{l}\text { Total plant respiration } \\
\quad\end{array}$ & & & & & \\
$\quad$ versus total plant N & & & & & & \\
$\begin{array}{l}\text { Field/US tree saplings } \\
\text { GH/tree seedlings }\end{array}$ & 118 & 2.985 & 1.182 & 1.114 & 1.253 & 0.952 \\
$\begin{array}{l}\text { GH/herb seedlings } \\
\text { All }\end{array}$ & 62 & 2.889 & 0.960 & 0.905 & 1.109 & 0.975 \\
$\begin{array}{l}\text { Above-ground plant } \\
\quad \text { respiration versus }\end{array}$ & 315 & 2.922 & 1.028 & 1.004 & 1.052 & 0.979 \\
$\quad$ above-ground plant N & & & & & & \\
All & 381 & 2.920 & 1.048 & 1.027 & 1.069 & 0.981
\end{tabular}

Shown are data from four experiments (as in Table 1), as well as the relation of aboveground respiration versus $\mathrm{N}$ for all data pooled, including additional data points for Japanese trees (see Fig. 1f). For the $\mathrm{GC} /$ tree seedling study, the plant $\mathrm{N}$ versus plant mass relation is shown for shoot (stem plus foliage) $\mathrm{N}$ and mass, because no root $\mathrm{N}$ data are available. lower tissue $\mathrm{N}$ concentration and a lower elevation of the scaling relation) than did first-year plants grown in the greenhouse or growth chambers (Fig. 1c, f). Fitting a single relationship across all data, total plant $\mathrm{N}$ scales as the 0.81-power of total mass $(95 \%$ $\mathrm{CI}=0.80-0.82$ ), but plots of residuals versus predicted values again indicate that a single overall model fit is inappropriate. Similarly, across all data, plant $\mathrm{N}$ per unit mass (that is, $\mathrm{N}$ concentration) declines significantly $(P<0.05)$ with increasing plant mass, although this relationship is a result of a clustering of clouds of data points (representing individual studies) in different positions along the axes, and is significant in only two of our four individual data sets.

The mechanistic coupling of plant respiration and N (refs 15-18), the universal scaling of respiration and $\mathrm{N}$ (Fig. 1b, e), and variability in plant $\mathrm{N}$ concentration provide a physiologically based explanation, first, for isometric scaling of respiration to mass in studies that encompass both ontogenetic and interspecific variation in contrasting growth environments; second, for differences in the intercept of this relationship among studies; and third, for the non-isometric scaling of respiration versus mass across all data pooled. In effect, the lower intercept (elevation) of the respirationmass scaling relation of the wild field-grown saplings in Minnesota or plantation trees in Japan as compared with the laboratory-grown seedlings (Fig. 1a, d) can be explained by their lower $\mathrm{N}$ content or concentration at a given plant size (Fig. 1c, f).

The results of our study of respiration and body size in whole plants provide no support for a key prediction of the theory of $\frac{3}{4}$-power scaling of metabolism to body mass. Instead, these data indicate that there is no universal, fixed scaling of respiration versus size in plants, because individual studies have similar, near isometric (exponent $\approx 1.04$ ) scaling within data sets, but can differ in intercept, resulting in a (statistically problematic) scaling exponent of $<1.0$ but $>0.75$ across the widest range in plant sizes. By contrast, the only relationship common across all data in our compilation is that relating respiration per plant and $\mathrm{N}$ per plant.

Why should plant metabolism scale as $\sim 1.0$-power of $\mathrm{N}$ and not as $\sim \frac{3}{4}$-power of mass? First, plant tissues require $\mathrm{N}$ as a chief component of key enzymes to carry on crucial metabolic processes. Specific rates of respiration and $\mathrm{N}$ concentration in plant leaves and roots are often positively correlated, especially for broad comparisons among species $^{15-18}$. In our study, when respiration and $\mathrm{N}$ are expressed per unit mass, whole-plant specific respiration rate scales positively with 
$\mathrm{N}$ per unit mass (that is, $\mathrm{N}$ concentration) within studies and across all data pooled (exponent $=1.17,95 \% \mathrm{CI}=1.11-1.24$ ), although the fits are poorer than those for whole plants (data not shown). The strong physiological coupling of respiratory metabolism with $\mathrm{N}$, in combination with an overall range of percentage $\mathrm{N}$ that is modest compared with the enormous range of total $\mathrm{N}$ content across size, apparently leads to common and roughly isometric respiration-N relations across all plants.

Second, the isometric scaling of respiration rate and $\mathrm{N}$ does not lead to $\mathrm{a} \frac{3}{4}$-power scaling of respiration to mass, as it would if $\mathrm{N}$ scaled as the $\frac{3}{4}$-power of mass. Although the $\frac{3}{4}$-power law scaling in animals has been explained to result from the efficient design of exchange surfaces and vascular distribution networks, the $\mathrm{N}$ concentration in any given plant tissue and the total $\mathrm{N}$ content in any given plant are not just a passive reflection of vascular networks. The concentration and total pools of $\mathrm{N}$ in any plant are in part governed by mechanisms involved in $\mathrm{N}$ uptake, initial allocation and subsequent resorption and redistribution. For example, perennial plants resorb roughly half of the $\mathrm{N}$ in leaves before they are shed, which supplies a sizeable fraction of future plant $\mathrm{N}$ demand. Taxa differ at the leaf and wholeplant level in the magnitude of this proportional $\mathrm{N}$ recovery and thus in the fraction of future $\mathrm{N}$ demand met by this conserved $\mathrm{N}$. This is one example of an important mechanism in plants that can partially uncouple $\mathrm{N}$ content from constraints of the vascular network.

In addition, other aspects of plant respiration are less tightly linked to vascular networks than are similar processes in animals. Plants and animals differ fundamentally in $\mathrm{O}_{2}$ and $\mathrm{CO}_{2}$ exchange processes. At the capillaries-the end points of the vascular delivery system in animals - the supply of all principal resources $\left(\mathrm{O}_{2}\right.$, carbon substrates and mineral elements) required for respiratory metabolism is constrained by the geometry of the vascular network. By contrast, in plants the most metabolically active tissues_leaves_are at the distal ends of the delivery network for nutrients and water, but $\mathrm{O}_{2}$ and $\mathrm{CO}_{2}$ are exchanged with the atmosphere by diffusion directly into leaves, with an additional set of factors further constraining these fluxes. Furthermore, substrate supply to mitochondrial respiration in plants is linked to carbohydrates produced in photosynthesis, with sourcesink relationships governing internal transport, which may also uncouple metabolism from vascular constraints. Thus, respiratory metabolism in plants is linked to N-rich enzymes, substrate supply and adenylate demand ${ }^{15-18}$, which are not necessarily under dominant control by vascular constraints. Finally, research suggests that there may not be universal allometric scaling of hydraulic architecture and water transport in plants ${ }^{29,30}$. Consequently, even the supply of resources such as water that logically should be constrained by the plant hydraulic network, may not be as uniformly controlled by that system as has been proposed ${ }^{8,12}$. Thus, the processes that influence respiration in plants stand in contrast to those in animals where the supply of respiratory substrate and oxygen and $\mathrm{CO}_{2}$ gas exchange may be more closely constrained by vascular networks.

In summary, we consistently observed near isometric scaling of whole-plant respiration, $\mathrm{N}$ content and plant mass in experiments that each included various vascular plant taxa and growing environments, and common scaling of total plant respiration to total plant $\mathrm{N}$ across all taxa, environments and experiments. These results are consistent with the notion of convergent scaling of metabolism to tissue $\mathrm{N}$ concentration ${ }^{16-18}$. Moreover, these findings are different than the $\frac{3}{4}$-power scaling found for metabolism and body size in animals, and suggest that the notion of a single general law of sizedependent metabolism ${ }^{12-14}$ may be premature. Developing general scaling models that can predict scaling relationships for both plants and animals represents an important challenge to biology and ecology.

\section{METHODS}

Data compilation. The data used in these analyses were compiled from several studies designed to address questions about environmental effects (for example, light level, temperature or atmospheric $\mathrm{CO}_{2}$ concentration) on plant growth, morphology and physiology (Supplementary Information), including whether these varied with plant size, but these data were not previously used to assess broad issues of metabolic scaling among plant taxa or environmental conditions.

Our data compilation for whole plants included coupled measurements of dark respiration rates, plant size and $\mathrm{N}$ content for first-year plants grown from seed in laboratory or greenhouse conditions in three separate experiments, and for 6- to 25-yr-old tree saplings growing naturally in a temperate forest. Because all species inhabit the temperate zone, respiration measurements were made during the growing season summer or summer-like conditions in controlled environments. The three seedling studies included GH/tree seedlings: a greenhouse experiment with nine cold temperate tree species grown in shaded and unshaded conditions ( $n=165$ seedlings measured for respiration); GC/tree seedlings: a growth chamber experiment with five cold temperate tree species growing in contrasting atmospheric $\mathrm{CO}_{2}$ concentrations and in three different temperature regimes $(n=190$ seedlings); and $\mathrm{GH} /$ herbs: a greenhouse experiment with 32 herbaceous grassland species (including grasses and forbs) growing in ambient or $\mathrm{N}$-enriched soil ( $n=62$ seedlings). A fourth study (Field/US tree saplings) involved naturally regenerated saplings of four cold temperate tree species growing in contrasting light microhabitats (understory and small gap) in a forest in northern Minnesota, USA ( $\mathrm{n}=119$ seedlings).

Measurements. Dark respiration rates were measured by infrared gas analysis of net $\mathrm{CO}_{2}$ efflux at temperatures near growth temperatures for the intact foliage, stem (or foliage plus stem), and root systems of individual plants, and then aggregated to the whole plant (see Supplementary Information for details). In addition, to extend the range of plant sizes to encompass large trees (Field/Japan trees), we compiled published above-ground data on night time net $\mathrm{CO}_{2}$ efflux collected during the summer on ten Chamaecyparis obtusa trees ${ }^{27,28}$. Where necessary, we adjusted all respiration rates to a common measurement temperature $\left(24^{\circ} \mathrm{C}\right)$ by using a published temperature model ${ }^{15}$ to reconcile measurement temperature differences among studies. Results are similar using data adjusted to a common temperature, data reported at growth temperature, or data recorded at measurement temperatures (see Supplementary Information for details).

Data analysis. Standardized major axis slopes were fitted to bivariate trait relationships of log-transformed variables using type II linear regression. The slope of such lines represents the proportional (scaling) relationship and is equivalent to the scaling exponent of the power law (equation (1)). We also used analysis of covariance, which is based on type I linear regression, to test for slope differences among groups and, when slopes were similar, for intercept differences in the relations of the log-transformed variables.

\section{Received 20 June; accepted 29 September 2005.}

1. Kleiber, M. Body size and metabolism. Hilgardia 6, 315-353 (1932).

2. Peters, R. H. The Ecological Implications of Body Size (Cambridge Univ. Press, Cambridge, MA, 1983).

3. Calder, W. A. Size, Function, and Life History (Harvard Univ. Press, Cambridge, MA, 1984).

4. Savage, V. M. et al. The predominance of quarter-power scaling in biology. Funct. Ecol. 18, 257-282 (2004).

5. Riisgård, H. U. No foundation of a ' $3 / 4$ power scaling law' for respiration in biology. Ecol. Lett. 1, 71-73 (1998).

6. Dodds, P. S., Rothman, D. H. \& Weitz, J. S. Re-examination of the $\frac{3}{4}$-law of metabolism. J. Theor. Biol. 209, 9-27 (2001).

7. White, C. R. \& Seymour, R. S. Mammalian basal metabolic rate is proportional to body mass. Proc. Natl Acad. Sci. USA 100, 4046-4049 (2003).

8. West, G. B., Brown, J. H. \& Enquist, B. J. A general model for the origin of allometric scaling laws in biology. Science 276, 122-126 (1997).

9. West, G. B., Brown, J. H. \& Enquist, B. J. The fourth dimension of life: fractal geometry and allometric scaling of organisms. Science 284, 1677-1679 (1999).

10. Banavar, J. R., Maritan, A. \& Rinaldo, A. Size and form in efficient transportation networks. Nature 399, 130-134 (1999).

11. Banavar, J. R., Damuth, J., Maritan, A. \& Rinaldo, A. Supply-demand balance and metabolic scaling. Proc. Natl Acad. Sci. USA 99, 10506-10509 (2002).

12. West, G. B., Brown, J. H. \& Enquist, B. J. A general model for the structure, and allometry of plant vascular systems. Nature 400, 664-667 (1999).

13. Gillooly, J. F., Brown, J. H., West, G. B., Savage, V. M. \& Charnov, E. L. Effects of size and temperature on metabolic rate. Science 293, 2248-2251 (2001)

14. Brown, J. H., Gillooly, J. F., Allen, A. P., Savage, V. M. \& West, G. B. Toward a metabolic theory of ecology. Ecology 85, 1771-1789 (2004)

15. Atkin, O. K. \& Tjoelker, M. G. Thermal acclimation and the dynamic response of plant respiration to temperature. Trends Plant Sci. 8, 343-351 (2003).

16. Ryan, M. G. Foliar maintenance respiration of subalpine and boreal trees and shrubs in relation to nitrogen content. Plant Cell Environ. 18, 765-772 (1995).

17. Reich, P. B. et al. Relationships of leaf dark respiration to leaf nitrogen, specific 
leaf area and leaf life-span: a test across biomes and functional groups. Oecologia 114, 471-482 (1998)

18. Wright, I. J. et al. The worldwide leaf economics spectrum. Nature 428 , 821-827 (2004).

19. Kozlowski, J. \& Konarzewski, M. Is West, Brown and Enquists model of allometric scaling mathematically correct and mathematically relevant? Funct. Ecol. 18, 283-289 (2004).

20. Enquist, B. J., Brown, J. H. \& West, G. B. Allometric scaling of plant energetics and population density. Nature 395, 163-166 (1998)

21. Reich, P. B. Body size, geometry, longevity and metabolism: do plant leaves behave like animal bodies? Trends Ecol. Evol. 16, 674-680 (2001).

22. Enquist, B. J. Universal scaling in tree and vascular plant allometry: towards a general quantitative theory linking plant form and function from cells to ecosystems. Tree Phys. 22, 1045-1064 (2002).

23. Enquist, B. J. \& Niklas, K. J. Global allocation rules for biomass partitioning in seed plants. Science 295, 1517-1520 (2002).

24. Niklas, K. J. \& Enquist, B. J. On the vegetative biomass partitioning of seed plant leaves, stems, and roots. Am. Nat. 159, 482-497 (2002).

25. Niklas, K. J. \& Enquist, B. J. Invariant scaling relationships for interspecific plant biomass production rates and body size. Proc. Natl Acad. Sci. USA 98, 2922-2927 (2001).

26. Enquist, B. J. et al. Scaling metabolism from organisms to ecosystems. Nature 423, 639-642 (2003)

27. Yokota, T., Ogawa, K. \& Hagihara, A. Dependence of the above-ground respiration of hinoki cypress (Chamaecyparis obtusa) on tree size. Tree Physiol. 14, 467-479 (1994)

28. Yokota, T. \& Hagihara, A. Changes in the relationship between tree size and aboveground respiration in field-grown hinoki cypress (Chamaecyparis obtusa) trees over three years. Tree Physiol. 18, 37-43 (1998).

29. Meinzer, F. C., Bond, B. J., Warren, J. M. \& Woodruff, D. R. Does water transport scale universally with tree size? Funct. Ecol. 19, 558-565 (2005).

30. McCulloh, K. A. \& Sperry, J. S. Patterns in hydraulic architecture and their implications for transport efficiency. Tree Physiol. 25, 257-267 (2005).

Supplementary Information is linked to the online version of the paper at www.nature.com/nature.

Acknowledgements We thank the Wilderness Research Foundation and the National Science Foundation Long-Term Ecological Research Program for major support of the research reported herein and the Gordon Conference 'Metabolic Basis of Ecology' for inspiring us in this endeavour.

Author Contributions The idea behind this paper was developed by P.B.R. and J.-L.M. while attending the Gordon Conference Metabolic Basis of Ecology. P.B.R. did the statistical analyses and wrote the paper with considerable assistance from M.G.T. All authors interpreted the results, commented on the manuscript and were involved in the design and implementation of one or more of the individual studies that collectively make up this paper (P.B.R., four studies; M.G.T., three; J.-L.M., two; J.O., one).

Author Information Reprints and permissions information is available at npg.nature.com/reprintsandpermissions. The authors declare no competing financial interests. Correspondence and requests for materials should be addressed to P.B.R. (preich@umn.edu). 